Artigo original

Hegemonia - Revista Eletrônica do Programa de Mestrado em Direitos Humanos, Cidadania e Violência/Ciência Política do Centro Universitário Unieuro

ISSN: $1809-1261$

UNIEURO, Brasília, número 26, Janeiro a Junho de 2019, pp. 114-151.

Recebido em: 28/05/2018

Avaliado em: 5/09/2018

Aprovado em: 18/11/2018

\title{
JUDICIALIZAÇÃO NA GESTÃO DO HOSPITAL DA CRIANÇA DE BRASÍLIA: O IMPACTO DE UMA DECISÃO JURÍDICA À LUZ DA PERSPECTIVA DO BEM SOCIAL
}

\author{
Cristina Melo Gonçalves ${ }^{1}$ e Ida Geovanna Medeiros da Costa ${ }^{2}$
}

RESUMO: Nas palavras do ilustre professor e atual ministro do Supremo Tribunal Federal, Luís Roberto Barroso, judicialização significa que "algumas questões de larga repercussão política ou social estão sendo decididas por órgãos do Poder Judiciário, e não pelas instâncias políticas tradicionais" e, complementa, ainda, "a primeira grande causa da judicialização foi a redemocratização do país, que teve como ponto culminante a promulgação da Constituição de 1988". Dessa forma, tendo em vista o conceito proposto pelo ministro, o presente artigo reflete sobre o tema da judicialização na área da saúde, levando-se em consideração o estudo de um caso concreto, qual seja, a decisão do juiz titular da $7^{a}$ Vara da Fazenda Pública, Paulo Afonso Cavichioli Carmona, que condenou a Organização Social (OS), ICIPE (Instituto do Câncer Infantil e Pediatria Especializada), - responsável por administrar o Hospital da Criança de Brasília José Alencar (HCB) - por improbidade administrativa e violação de importantes princípios e afronta à outras legislações do Direito Administrativo, em contrapartida com a decisão do relator desembargador, Alfeu Machado, do Tribunal de Justiça do Distrito Federal (TDFT) estabelecendo, assim, de modo objetivo, suas características, alcance, objetivos, importância e, também, consequências.

PALAVRAS-CHAVE: Judicialização. Saúde. Hospital da Criança de Brasília. Bem social.

ABSTRACT: In the words of the illustrious teacher and current minister of the Federal Supreme Court, Luís Roberto Barroso, judicialization means that "some questions of long political repercussion or social are being decided by organs of the Judiciary, and not by traditional political instances" and, complements, still, "the first great cause of the judicialization was the re-democratization of the country, that had as high point the promulgation of the Constitution of 1988". In this way, in view of the concept proposed by the minister, this article reflects on the theme of judicialization in the health area, taking into

\footnotetext{
${ }^{1}$ Doutoranda em Parcerias na Saúde pela Universidade de Brasília e Docente do Centro Universitário EuroAmericano.

2 Pesquisadora de Iniciação científica do Centro Universitário Unieuro.
} 
Artigo original

Hegemonia - Revista Eletrônica do Programa de Mestrado em Direitos Humanos, Cidadania e Violência/Ciência Política do Centro Universitário Unieuro

ISSN: 1809-1261

UNIEURO, Brasília, número 26, Janeiro a Junho de 2019, pp. 114-151.

consideration the study of a concrete case, which is, the decision of the titular judge of the $7^{\text {th }}$ Court of the Theasury, Paulo Afonso Cavichioli Carmona, that condemned the social organization (OS), ICIPE (Institute of Childhood Cancer and Specialized Pediatrics), responsible for administer the Childen's Hospital of Brasilia José Alencar (HCB) - for administrative dishonesty and violation of important principles and affront to others legislatons of Adminisrative Law, in contrast with the decision of the debtor rapporteur, Alfeu Machado, of the Federal District Court of Justice (TJDFT), establishing, therefore, so objectively, your characteristics, reach, goals, importance and, also, consequences.

KEYWORDS: Judicialization. Health. Childen’s Hospital of Brasília. Social good.

1 - Introdução: Origem do Hospital da Criança de Brasília José Alencar (HCB) e ABRACE/ICIPE

A origem do Hospital da Criança de Brasília José Alencar (HCB), seu deu, a partir do momento em que profissionais da pediatria (pediatria do Hospital de Base), juntamente com pais de crianças internadas, iniciaram um projeto com intuito de promover uma melhor qualidade na assistência à saúde direcionada às crianças e adolescentes. Isso foi possível, por meio da criação da Associação Brasileira de Assistência às Famílias de Crianças Portadoras de Câncer e Hemopatias (ABRACE) e da Casa de Apoio, destinada à crianças e adolescentes com câncer e hemopatias que, além do tratamento, necessitavam de moradia durante a sua duração.

Dessa forma, nasce o Hospital da Criança de Brasília, mais conhecido como HCB que, - aliás, não atende só crianças com câncer e hemopatias na Rede SES/DF, possuindo mais outras 17 especialidades - também, passou a ter apoio de outros segmentos sociais e políticos do Distrito Federal.

Aliás, nas palavras de Renilsson Rehen, superintendente executivo, numa entrevista disponível no site do HCB, publicada em 2016, os números apontam para a importância de se ter criado o Hospital que também pertence à rede de saúde pública do Distrito Federal:

O Hospital pertence à rede de saúde pública do Distrito Federal e já realizou, nos últimos quatro anos, dois milhões e 15 mil atendimentos. Foi necessário não somente para as 
Artigo original

Hegemonia - Revista Eletrônica do Programa de Mestrado em Direitos Humanos, Cidadania e Violência/Ciência Política do Centro Universitário Unieuro

ISSN: 1809-1261

UNIEURO, Brasília, número 26, Janeiro a Junho de 2019, pp. 114-151.

crianças e adolescentes, mas também para toda a rede pública de saúde do DF, que pôde contar com mais essa unidade de tratamento. Mais de 30 mil crianças são pacientes do Hospital. E, a cada mês, 600 novas vagas de dezessete especialidades são oferecidas pela central de regulação do Distrito Federal. (BRASÍLIA, Hospital da Criança de. HCB. Entrevista esclarece funcionamento do HCB, pergunta $\left.n^{\circ} 1,2016\right)$

Ainda nas palavras de Rehen, a construção do hospital se deu por meio da cessão de uso de um terreno, realizada pelo GDF, com recursos doados pela comunidade para a ABRACE e, após a construção, ao patrimônio do Distrito Federal:

O convênio assinado entre a SES/DF e a Abrace em 2004 (Convênio no 014/2004 da SES/DF, em anexo) permitia o uso do terreno, de propriedade da SES/DF, pela Abrace, para a construção do Hospital da Criança de Brasília, na época ainda chamado de Instituto Pediátrico. Neste mesmo convênio, estava previsto que, após a construção do $\mathrm{HCB}$, o prédio seria incorporado ao patrimônio do Distrito Federal. (BRASÍLIA, Hospital da Criança de. HCB. Entrevista esclarece funcionamento do $H C B$, pergunta $n^{\circ}$ 4, 2016)

No entanto, houve um questionamento, no ano de 2007, quanto à cessão de uso do terreno por meio do Ministério Público, junto ao Tribunal de Contas do DF, trata-se da representação $n^{\circ} 34 / 2007-C F$, que originou o processo $n^{\circ} 41.101 / 2007$, no TCDF e, que após avaliação do mesmo, em sessão ordinária no 4.780 de 02/06/2015, por meio da decisão $\mathrm{n}^{\circ} 2.181 / 2015$, o mesmo órgão autorizou o arquivamento dos autos, por unanimidade: 
Artigo original

Hegemonia - Revista Eletrônica do Programa de Mestrado em Direitos Humanos, Cidadania e Violência/Ciência Política do Centro Universitário Unieuro

ISSN: 1809-1261

UNIEURO, Brasília, número 26, Janeiro a Junho de 2019, pp. 114-151.

O Tribunal, por unanimidade, de acordo com o voto da Relatora, decidiu: I - tomar conhecimento do: a) Ofício n ${ }^{\circ}$ 3361/2014-GAB/SES e anexos (fls. 691/709), para atendimento ao item II da decisão n ${ }^{\circ}$ 4702/2014; b) pedido de informações do Ministério Público Federal acerca dos processos $\mathrm{n}^{\mathrm{o}} \mathrm{s} 41.101 / 07$ e 24.165/11 (fl. 711), atendido por meio do Ofício no 328/2014-P/AA (fl. 715;) II considerar cumprida a Decisão no 4.702/2014; III autorizar o arquivamento dos autos. (BRASÍLIA, Hospital da Criança de. HCB. Entrevista esclarece funcionamento do $H C B$, pergunta $\left.n^{\circ} 4,2016\right)$

Quanto à criação de uma Organização Social para gestão do Hospital, se deu, segundo Rehen, pelo fato de ser considerada a ideia mais viável, seja por profissionais do Hospital de Base, Governo do Distrito Federal, seja pela sociedade que, nesse caso, é representada pela ABRACE (Associação Brasileira de Assistência às Famílias de Crianças Portadoras de Câncer e Hemopatias) - organização não-governamental com 32 anos de existência. Assim, explica Roberto Nogueira Ferreira, um dos fundadores da ABRACE e seu primeiro presidente, sobre a sua criação:

$1^{\circ}$ de maio de 1986. Nove pais e mães de crianças em tratamento de Leucemia no Hospital de Base de Brasília (HBB) reúnem-se e fundam a ABRACE - Associação Brasileira de Assistência às Famílias de Crianças Portadoras de Câncer e Hemopatias. Iniciava-se, naquele momento, uma guerra santa, transformadora de dor em amor. Recorro-me a Fernando Pessoa, o grande poeta lusitano, Todo começo é involuntário, Deus é o agente. Deus estava presente à sala de minha casa, onde eu e minha 
Artigo original

Hegemonia - Revista Eletrônica do Programa de Mestrado em Direitos Humanos, Cidadania e Violência/Ciência Política do Centro Universitário Unieuro

ISSN: $1809-1261$

UNIEURO, Brasília, número 26, Janeiro a Junho de 2019, pp. 114-151.

mulher (Maria Angela Marini, atual presidente da ABRACE) recepcionamos os outros cavaleiros da esperança e da fé.

A ABRACE é - desde de sua origem - uma Organização Não Governamental fora dos padrões convencionais. A ABRACE é um conceito cuja ideologia é o amor. Não há vínculos políticos, interesses econômicos, nem a intenção em ocupar espaços de natureza pública. Nascida para colaborar com o poder público, melhorar as condições de atendimento hospitalar e "abraçar" as crianças com câncer e seus pais, unidos em suas tragédias individuais. (FERREIRA, Roberto Nogueira. HOSPITAL DA CRIANÇA DE BRASÍLIA, ABRACE/ICIPE - HCB (A Brasília que deu certo)).

Além disso, uma vez criada, a ABRACE também cria o ICIPE (Instituto do Câncer Infantil e Pediatria Especializada), em 22/02/2009, conforme o Convênio no 014/2004 que, quanto à gestão do Hospital, além de outras funções a serem exercidas por esta organização, prevê:

Fica garantido e obrigam-se também os participes a celebrar, após o termino da obra, um novo acordo de vontades que poderá ser um outro convênio, contrato de gestão ou termo de parceria, se presentes os requisitos para tanto, pelo qual a Secretaria de Saúde do Distrito Federal e entidade que deverá ser futuramente constituída pela ABRACE, dividirão a responsabilidade pela gestão do novo Instituto Pediátrico. (BRASÍLIA, Hospital da Criança de. HCB. Entrevista esclarece funcionamento do HCB, pergunta $\left.n^{\circ} 25,2016\right)$ 
Artigo original

Hegemonia - Revista Eletrônica do Programa de Mestrado em Direitos Humanos, Cidadania e Violência/Ciência Política do Centro Universitário Unieuro

ISSN: 1809-1261

UNIEURO, Brasília, número 26, Janeiro a Junho de 2019, pp. 114-151.

2 - Decisão do juiz titular da $7^{a}$ Vara da Fazenda Pública

No entanto, tendo em vista as informações trazidas sobre a origem do HCB, ABRACE e ICIPE, no item anterior, em maio de 2018, o Conselho Administrativo do Instituto do Câncer Infantil e Pediatria Especializada (ICIPE), decidiu deixar a gestão do HCB, em razão de cumprimento de uma decisão judicial emitida em dezembro do ano anterior:

\section{SENTENÇA}

Vistos etc.

Cuida-se de ação civil pública por ato de improbidade administrativa proposta pelo MINISTÉRIO PÚBLICO DO DISTRITO FEDERAL E TERRITÓRIOS, por intermédio da $2^{\mathrm{a}}$ Promotoria de Justiça de Defesa da Saúde, em face de RAFAEL DE AGUIAR BARBOSA, ELIAS FERNANDO MIZIARA, MARCO AURÉLIO DA COSTA GUEDES e INSTITUTO DO CÂNCER INFANTIL E PEDIATRIA ESPECIALIZADA - ICIPE, devidamente qualificados nos autos.

Narra a inicial que a Associação Brasileira de Assistência às Famílias de Crianças Portadoras de Câncer e Hemopatias - ABRACE, representada por sua dirigente, ILDA RIBEIRO PELIZ, celebrou, com o Distrito Federal, o Convênio $n^{\circ}$ 014, cujo objeto consistia na "colaboração e atuação conjunta da Secretaria de Estado de Saúde do Distrito Federal e da ABRACE na construção do INSTITUTO PEDIÁTRICO - IP, hospital de pesquisa, diagnóstico e tratamento do câncer infantil, a ser efetivada nos termos do PLANO DE TRABALHO anexo" ao 
Artigo original

Hegemonia - Revista Eletrônica do Programa de Mestrado em Direitos Humanos, Cidadania e Violência/Ciência Política do Centro Universitário Unieuro

ISSN: 1809-1261

UNIEURO, Brasília, número 26, Janeiro a Junho de 2019, pp. 114-151.

convênio, tendo restado consignado, ainda, que os partícipes poderiam celebrar, após o término da obra, "outro convênio, contrato de gestão ou termo de parceria, se presentes os requisitos para tanto, pelo qual a Secretaria de Saúde do Distrito Federal e a entidade que deverá ser futuramente constituída pela ABRACE, dividirão a responsabilidade pela gestão do novo Instituto Pediátrico - IP."

Consta, ainda, da petição inicial, que referido convênio teve seu primeiro termo aditivo assinado, com alteração de seu prazo de vigência de sessenta meses para vinte anos.

Descreve a peça inaugural, ainda, que em manifesta violação aos princípios da impessoalidade e moralidade, a ABRACE foi contemplada com a concessão de direito real de uso, a título gratuito, do lote $04-\mathrm{B}$, no SAIN, onde foi erigido Hospital da Criança José de Alencar, sem procedimento licitatório, o que já demonstrava, inclusive, o propósito de beneficiar a mesma entidade com a gestão do hospital cuja construção ela havia contribuído, adotando-se a engenhosa mas ilícita solução de aparentemente impor-lhe a obrigação de constituir outra entidade e de qualificá-la como Organização Social para, e em contra partida, conceder-lhe a gestão compartilhada do Instituto Pediátrico, sem que esta OS jamais tivesse prestado qualquer atividade social anterior que pudesse fazê-la ser reconhecida como tal. (Carmona, Paulo Afonso Cavichioli, TJDFT, juiz titular da $7^{\mathrm{a}}$ Vara da Fazenda Pública, Sentença).

Em sua decisão, o juiz titular da $7^{a}$ Vara da Fazenda Pública, Paulo Afonso Cavichioli Carmona, entendeu que, tanto os requisitos necessários para qualificação do ICIPE como 
Artigo original

Hegemonia - Revista Eletrônica do Programa de Mestrado em Direitos Humanos, Cidadania e Violência/Ciência Política do Centro Universitário Unieuro

ISSN: 1809-1261

UNIEURO, Brasília, número 26, Janeiro a Junho de 2019, pp. 114-151.

organização social, quanto à celebração do contrato de gestão, dentre outras questões, não respeitaram as determinações legais:

Esclareceu o órgão ministerial, ainda, que em 23/06/2009 foi criado Instituto do Câncer Infantil e Pediatria Especializada - ICIPE, com mesma sede social da ABRACE, sendo que em menos de seis meses de funcionamento do referido instituto, houve a protocolização de pedido para torná-lo como Organização Social de Saúde com o interesse de firmar contrato de gestão na área de saúde, o qual foi deferido através do Decreto Distrital $\mathrm{n}^{\circ} \quad 32.755 / 2011$, ratificado posteriormente pelo Decreto Distrital no 32.980/2011.

Aduz, ainda, que no dia 27 de junho de 2011, foi publicado extrato de dispensa de licitação em favor do ICIPE, no valor total de $\mathrm{R} \$ 105.357 .609,00$, com validade de dois anos, sendo que não constou em referida publicação o objeto da dispensa.

Assenta, ainda, que em 11 de julho de 2011, foi publicado o Contrato de Gestão no 001/2011, firmado com o ICIPE, tendo por objeto a organização, implantação e gestão das ações de assistência à saúde no Hospital da Criança de Brasília - HCB, a serem prestados por sessenta meses, sendo que para a aquisição de equipamentos médicos hospitalares, mobiliário e outros materiais permanentes visando o adequado funcionamento do Hospital da Criação de Brasília a SES destinou à conveniada o valor total de $\mathrm{R} \$ 5.175 .695,68$, a serem liberados conforme cronograma de desembolso. 
Artigo original

Hegemonia - Revista Eletrônica do Programa de Mestrado em Direitos Humanos, Cidadania e Violência/Ciência Política do Centro Universitário Unieuro

ISSN: 1809-1261

UNIEURO, Brasília, número 26, Janeiro a Junho de 2019, pp. 114-151.

Salienta o Ministério Público que a escolha foi dirigida à ABRACE e ao ICIPE, de forma pessoal, unilateral e completamente dissociada das disposições da lei de licitações e de todo o regramento insculpido no artigo 37 da Constituição Federal, sendo que até o ano de 2014, o Distrito Federal já havia pago ao ICIPE, sem nenhum procedimento licitatório prévio, o valor de $\mathrm{R} \$ 102.009 .423,30$.

Frisou, também, que a qualificação do ICIPE como organização social não obedeceu aos ditames legais, em especial a regularidade jurídico-fiscal e a satisfatória situação econômica financeira da entidade, além de não ter havido a comprovação de experiência técnica para o desempenho das atividades previstas no contrato de gestão, sendo certo que o ICIPE foi criado com a finalidade exclusiva de assumir a gestão do Hospital da Criança de Brasília.

Assevera, também, que a criação do ICIPE foi arquitetada pelos réus com o nítido intento de afastar a concorrência com outras organizações sociais, socorrendo-se da existência de um convênio assinado no passado, entre as partes, no qual se previa cláusula específica, nula de pleno direito.

Frisa, ainda, que o chamamento público $\mathrm{n}^{\circ}$ 01/2011, publicado no DODF, não atendeu ao regramento legal.

Relatou, também, que o projeto básico de contratação não ficou disponível para consulta dos interessados, o que significa que SES/DF não tornou pública sua intenção de firmar contrato de gestão para gerir o Hospital da Criança de Brasília, violando os princípios da publicidade e da isonomia. 
Artigo original

Hegemonia - Revista Eletrônica do Programa de Mestrado em Direitos Humanos, Cidadania e Violência/Ciência Política do Centro Universitário Unieuro

ISSN: $1809-1261$

UNIEURO, Brasília, número 26, Janeiro a Junho de 2019, pp. 114-151.

Aduziu, ainda, que houve indevida contratação de mão de obra, violação à lei de responsabilidade fiscal, terceirização ilícita, sendo que tal modo de proceder mostra-se inaceitável, caracterizando a prática do ato ímprobo descrito no artigo 10, inciso VIII, da lei de improbidade administrativa, sendo certo que os três primeiros réus deixaram de dar crédito aos pareceres da PGDF, além de os atos terem sido praticados após a declaração de inconstitucionalidade da Lei $n^{\circ} 4.081 / 08$.

Afirma o Ministério Público, ainda, que o $1^{\circ}$ e $3^{\circ}$ requeridos devem ser responsabilizados por haverem permitido a indevida qualificação do ICIPE como organização social, apesar de todas as irregularidades apontadas.

Já o $1^{\circ}$ e $2^{\circ}$ réus são responsáveis por haverem permitido a contratação direita sem licitação e igualmente por violarem os princípios constitucionais da Administração Pública, sendo que o $2^{\circ}$ requerido por haver ratificado a dispensa indevida e a $4^{a}$ requerida, juntamente com o então Secretário de Saúde do DF, $1^{\circ}$ requerido, por haverem assinado os contratos referidos.

Aduz, ainda, que o ICIPE foi beneficiado pelo ato ímprobo, ensejando, com isso, na aplicação da norma contida no artigo $3^{\circ}$ da LIA.

Assenta, também, que para a configuração da conduta descrita no artigo 11 da LIA, mostra-se desnecessária a comprovação de enriquecimento ilícito do administrador público ou, ainda, a caracterização de prejuízo ao Erário. 
Artigo original

Hegemonia - Revista Eletrônica do Programa de Mestrado em Direitos Humanos, Cidadania e Violência/Ciência Política do Centro Universitário Unieuro

ISSN: $1809-1261$

UNIEURO, Brasília, número 26, Janeiro a Junho de 2019, pp. 114-151.

Entende o Ministério Público que as condutas dos réus se amoldam às figuras insculpidas no artigo 11, caput e incisos I e V, da Lei no 8.429/92.

Finaliza requerendo a condenação dos requeridos como incursos nas penas descritas no artigo 12, inciso III, da Lei de Improbidade Administrativa, nos termos indicados na peça exordial. (Carmona, Paulo Afonso Cavichioli, TJDFT, juiz titular da $7^{a}$ Vara da Fazenda Pública, Sentença).

Assim, tal decisão levou não só o ICIPE, mas, também, o Distrito Federal, a recorrer, pedindo a suspensão da sentença. Contudo, o pedido foi negado duas vezes, como mostra um trecho do Termo de Audiência de Conciliação em que o relator, é o desembargador Alfeu Machado:

"Trata-se de pedido antecipatório de efeito suspensivo a recurso de apelação formulado por INSTITUTO DO CÂNCER INFANTIL E PEDLATRLA ESPECIALIZADA ICIPE, visando a suspensão dos efeitos da sentença que em sede de ação civil pública por ato de improbidade administrativa movida pelo MINISTÉRIO PÚBLICO DO DISTRITO FEDERAL, condenou a recorrente, em concurso com outros réus, com fulcro nos artigos artigo 11, caput e inciso I, c/ c artigo $3^{\circ}$. da Lei $n^{\circ} 8.249 / 92$, à pena de "proibição de contratar com o Poder Público ou receber beneficios ou incentivos fiscais ou crediticios, direta ou indiretamente, ainda que por intermédio de pessoa jurídica da qual seja sócio majoritário pelo prazo de 3 (três) anos, a contar da prolação desta sentença."

Indeferido o pedido liminar de efeito suspensivo por não se constatar a presença dos pressupostos para tanto, o DISTRITO FEDERAL 
Artigo original

Hegemonia - Revista Eletrônica do Programa de Mestrado em Direitos Humanos, Cidadania e Violência/Ciência Política do Centro Universitário Unieuro

ISSN: 1809-1261

UNIEURO, Brasília, número 26, Janeiro a Junho de 2019, pp. 114-151.

compareceu aos autos requerendo sua babilitação como terceiro "jurídica e economicamente interessado" apenas no pedido antecipatório, aduzindo que mantém "posição de neutralidade" quanto ao mérito da ação originária.

Na oportunidade reiterou o pedido de efeito suspensivo, destacando a urgência da medida postulada.

O pedido de efeito suspensivo foi novamente indeferido, pois não apresentado argumentos fáticos e juridicos hábeis a infirmar a decisão anterior desta Relatoria, determinando-se a intimação das partes para se manifestarem sobre o pedido de assistência formulado pelo Distrito Federal, nos moldes dos artigos 119 e 120 do CPC.

Antes da remessa dos autos à Procuradoria de Justiça, veio aos autos pedido formulado pela Ordem dos Advogados do Brasil e pela Defensoria Pública do Distrito Federal, visando o ingresso na lide como amicus curiae, o que foi indeferido, já que o pedido visava esclarecer questões notórias e incontroversas no processo.

O ICIPE se manifestou nos autos no ID. 386589, reiterando sua irresignação e manifestando intenção de permanecer por trinta dias na Administração do Hospital da Criança para promover a transição da gestão, e no ID. 3911930 foi juntada cópia de processo administrativo instaurado pelo ICIPE perante o Presidente deste Egrégio Tribunal de Justiça, comunicando que solicitou a rescisão do contrato de gestão mantido com o Distrito Federal.

Diante de insistentes pedidos das partes e do Distrito Federal para que fossem recebidos em audiência particular com deste Desembargador, e considerando a comoção social que se instaurou quanto ao tema e a veiculação de informações falsas por agentes públicos quanto ao conteúdo da lide e objeto da condenação, designei a presente audiência de conciliação, a fim de se alcançar a resolução do impasse, por não haver outra forma no momento previsto do CPC. 
Artigo original

Hegemonia - Revista Eletrônica do Programa de Mestrado em Direitos Humanos, Cidadania e Violência/Ciência Política do Centro Universitário Unieuro

ISSN: 1809-1261

UNIEURO, Brasília, número 26, Janeiro a Junho de 2019, pp. 114-151.

E o faço para que não haja violação aos princípios da não surpresa, do efetivo contraditório e da imparcialidade que devem nortear a prestação jurisdicionais, e se alcance os primados dos princípios da paridade de almas e de colaboração processual. (MACHADO, Alfeu. TJDFT, relator desembargador, Termo de Audiência de Conciliação).

De acordo com uma nota do Conselho de Administração do ICIPE, apesar do Ministério Público do Distrito Federal (MPDFT) ter incluído o hospital em uma ação de improbidade administrativa, em 2015, o Tribunal de Contas do Distrito Federal (TCDF), teria aprovado a qualificação, bem como a regularidade do contrato de gestão estabelecido entre o instituto e o Governo do Distrito Federal. Assim, a decisão da justiça, pode causar sérios danos à saúde das crianças e adolescentes que, diariamente, são atendidas pelo hospital:

A excelência do Hospital da Criança de Brasília, que é referência em pediatria no País, é reconhecida pela mídia local e nacional, e por autoridades mundiais de saúde, como o Diretor Geral da Organização Mundial da Saúde (OMS), Tedros Adhanom Ghebreyesus, que declarou que o hospital é um modelo para o mundo.

Lidamos diariamente com doenças graves que podem levar a morte. São situações crônicas ou de alta complexidade. Cuidamos de 1.162 pacientes com câncer, 747 com anemia falciforme, 475 com anomalias neurológicas, $445 \mathrm{com}$ diabetes, 230 com imunodeficiência congênita, 200 com síndrome nefrótica, 110 com fibrose cística, $100 \mathrm{com}$ nepatite autoimune, 87 fazem transfusão regular, $70 \mathrm{com}$ doença inflamatória intestinal, 69 com doenças degenerativas neuromusculares, 52 fazem reposição regular de imunoglobulina, 43 transplantados de medula 
Artigo original

Hegemonia - Revista Eletrônica do Programa de Mestrado em Direitos Humanos, Cidadania e Violência/Ciência Política do Centro Universitário Unieuro

ISSN: 1809-1261

UNIEURO, Brasília, número 26, Janeiro a Junho de 2019, pp. 114-151.

óssea, 40 transplantados de fígado, 27 renais crônicos e 10

com mucopolissacaridose em infusão regular de enzima, além de milhares de outros com diversas patologias. (BRAZILIENSE, Correio. Instituto entrega gestão do Hospital da Criança de Brasilia ao GDF, 2018).

Nesse sentido, Roberto Nogueira Ferreira, não aprova a atitude do Ministério Público, bem como os motivos pelos quais, o ICIPE foi processado:

Eis que entra nessa história o Ministério Público do DF e Territórios, com a pretensão de alterar o modelo de gestão apoiado por quatro governadores eleitos pelo voto popular e um indicado (Roriz, Arruda, Rosso, Agnelo e Rollemberg). Sem o voto, o MP quer governar. Parece-me tão simples o conceito, que custo a crer que o MP desconheça que o efeito de sua ação seja a destruição do que vem dando certo.

Que razões impulsionam o MP, coincidentemente, a ser ativo na direção e no sentido de interesses já externados pelo corporativismo de servidores públicos? Por que deixar em plano secundário o "cliente" fundamental, desde a origem, que são as crianças com câncer e outras especialidades pediátricas?

Entendo o Ministério Público (meritória instituição nascida na Constituição de 1988) como advogado da sociedade e dos legítimos interesses sociais e gostaria de saber que uma parte dele o leva a desejar que o criador se afaste da criatura. Se há correções a serem feitas, indiqueas. (FERREIRA, Roberto Nogueira. HOSPITAL DA 
Artigo original

Hegemonia - Revista Eletrônica do Programa de Mestrado em Direitos Humanos, Cidadania e Violência/Ciência Política do Centro Universitário Unieuro

ISSN: 1809-1261

UNIEURO, Brasília, número 26, Janeiro a Junho de 2019, pp. 114-151.

CRIANÇA DE BRASÍLIA, ABRACE/ICIPE - HCB (A

Brasília que deu certo)).

Ainda em suas palavras, o ex-presidente da ABRACE, entende que, apesar de haver toda uma legalidade que deve ser cumprida, a assistência à sociedade se sobrepõe à essa legalidade e é o que deve ser cumprida:

A Constituição Federal assegura que a "saúde é direito de todos e dever do Estado", mas não se ocupou em dizer como o Estado deve prestar esse serviço, se diretamente por meio de funcionários públicos ou por meio de parcerias inovadoras. Certamente os constituintes entenderam que o essencial é a atenção a saúde deve chegar ao povo com eficiência e gratuidade. E é exatamente isso o que faz a parceria ABRACE/CIPE - SES - e Hospital da Criança de Brasília José Alencar. (FERREIRA, Roberto Nogueira. HOSPITAL DA CRIANÇA DE BRASÍLIA, ABRACE/ICIPE - HCB (A Brasília que deu certo)).

Também por meio de nota, o MPDFT se posiciona, representado pela Promotoria de Justiça de Defesa da Saúde (Prosus) que informou que um dos motivos para o órgão ter entrado com a ação, foi por considerar que o ICIPE não cumpria alguns dos requisitos necessários para o desempenho das atividades no HCB:

Para o Prosus, o Icipe não possuía experiência técnica para o desempenho das atividades e não preenchia os requisitos legais para se qualificar como organização social. Também não foi realizado chamamento público para que outras entidades interessadas pudessem candidatar-se a gerir o 
Artigo original

Hegemonia - Revista Eletrônica do Programa de Mestrado em Direitos Humanos, Cidadania e Violência/Ciência Política do Centro Universitário Unieuro

ISSN: $1809-1261$

UNIEURO, Brasília, número 26, Janeiro a Junho de 2019, pp. 114-151.

Hospital da Criança. No entendimento da Prosus, foram feridos os princípios da legalidade, da isonomia, da impessoalidade e da moralidade. (BRAZILIENSE, Correio. Instituto entrega gestão do Hospital da Criança de Brasilia ao GDF, 2018).

3 - Improbidade Administrativa e violação dos princípios do Direito Administrativo

Tendo em vista os fatos e dispositivos, por ora, apresentados, bem como o estudo da lide que tem como réu, o ICIPE, por terem sido detectadas irregularidades durante à gestão do mesmo, sobre o significado da palavra irregularidade, o dicionário jurídico, Vocabulário Jurídico, $24^{a}$ edição, de Plácido e Silva, aponta o seguinte significado para a palavra, dando luz à reflexão de que quando há irregularidade, há infração e, consequentemente, quando há infração, não há aplicação de uma lei, de uma regra:

IRREGULARIDADE. Derivado do latim irregularitas (de modo irregular, contrário à regularidade), quer exprimir tudo que se faz contra a regra ou em infração ao que está estabelecido, seja pela lei ou pelo próprio estilo.

Juridicamente, a irregularidade, contravenção ou infração à regra, sempre se mostra um defeito, que atinge tudo que se faz de modo irregular ou não conforme às prescrições que devem ser atendidas. Mas, nem sempre, a irregularidade formula um defeito substancial ou intrinseco que possa afetar visceralmente a validade do ato, assim praticado.

Quando, no entanto, a irregularidade é consequente de desatenção à regra necessária à validade do que se fez, pode trazer vício irremovível, que resulta na invalidade do ato. 
Artigo original

Hegemonia - Revista Eletrônica do Programa de Mestrado em Direitos Humanos, Cidadania e Violência/Ciência Política do Centro Universitário Unieuro

ISSN: $1809-1261$

UNIEURO, Brasília, número 26, Janeiro a Junho de 2019, pp. 114-151.

Em qualquer caso, porém, exprimindo o que é mal feito, consequentemente foi feito em contravenção ou infração ao que estava prescrito ou determinado, a irregularidade termina afastando da ação ou ato irregular a proteção da própria lei, enquanto não for cumprido o que é regra. (SILVA, De Plácido e, Vocabulário Jurídico, 2004)

Assim, conforme sentença do juiz de primeira instância, e a identificação de violação da Lei de Improbidade Administrativa, para Marino Pazzaglini Filho, no que diz respeito ao seu conceito, trata-se de uma corrupção administrativa que promove e desvirtua os objetivos da Administração Pública, além de ferir os princípios constitucionais e do direito administrativo. Existe quando se obtém alguma vantagem patrimonial por meio do erário e do exercício de função ou emprego público, existindo, assim, um tráfico de influência nas esferas da Administração Pública ou favorecimento de um grupo minoritário em desfavor de um grupo majoritário, qual seja, a própria sociedade, daí porque o dicionário jurídico expressa o significado da palavra da seguinte forma:

IMPROBIDADE. Derivado do latim improbitas (má qualidade, imoralidade, malícia), juridicamente, liga-se ao sentido de desonestidade, má fama, incorreção, má conduta, má indole, mau caráter. Desse modo, improbidade revela a qualidade do homem que não procede bem, por não ser honesto, que age indignamente, por não ter caráter, que não atua com decência, por ser amoral. Improbidade é a qualidade do ímprobo. E ímprobo é o mau moralmente, é o incorreto, o transgressor das regras da lei e da moral.

Para os romanos, a improbidade impunha a ausência de existimatio, que atribui aos homens o bom conceito. E sem a existimatio, os homens se convertem em homines, intestabiles, tornando-se inábeis, portanto, sem a capacidade ou indoneidade para a prática de certos atos. 
Artigo original

Hegemonia - Revista Eletrônica do Programa de Mestrado em Direitos Humanos, Cidadania e Violência/Ciência Política do Centro Universitário Unieuro

ISSN: $1809-1261$

UNIEURO, Brasília, número 26, Janeiro a Junho de 2019, pp. 114-151.

Improbidade. $\mathrm{Na}$ terminologia das leis trabalhistas, a improbidade é a desonestidade, a falta de retidão, o procedimento malicioso, a autuação perniciosa. E o empregado que se enquadra na improbidade dá razões para que seja justamente despedido.

A improbidade demonstrada é, pois, justa causa para a dispensa do empregado, sem direito, portanto, a qualquer indenização. (SILVA, De Plácido e, Vocabulário Jurídico, 2004)

Ainda para Pazzaglini, de forma geral, a improbidade administrativa não reclama tanta elaboração para que seja reconhecida, uma vez que estará caracterizada "sempre que a conduta administrativa contrastar qualquer dos princípios fixados no art. 37, caput da CF (legalidade, impessoalidade, moralidade e publicidade), independentemente da geração de efetivo prejuízo ao erário". Assim, a lei no 8.429 , em seu artigo $1^{\circ}$, define quem são os sujeitos ativos e passivos da improbidade administrativa:

Art. $1^{\circ}$ Os atos de improbidade praticados por qualquer agente público, servidor ou não, contra a administração direta, indireta ou fundacional de qualquer dos Poderes da União, dos Estados, do Distrito Federal, dos Municípios, de Território, de empresa incorporada ao patrimônio público ou de entidade fora para cuja criação ou custeio o erário haja concorrido ou concorra com mais de cinquenta por cento do patrimônio ou da receita anual, serão punidos na forma desta lei. (ADMINISTRATIVA, Lei de Improbidade, No 8.429 de 2 de junho de 1992.

Além disso, como uma das características da violação da Lei de Improbidade Administrativa, é quando há a violação dos princípios constitucionais e do direito administrativo, decorrentes de uma corrupção administrativa que promove e desvirtua os 
Artigo original

Hegemonia - Revista Eletrônica do Programa de Mestrado em Direitos Humanos, Cidadania e Violência/Ciência Política do Centro Universitário Unieuro

ISSN: 1809-1261

UNIEURO, Brasília, número 26, Janeiro a Junho de 2019, pp. 114-151.

objetivos da Administração Pública, prevê o artigo 37 da Constituição da República Federativa do Brasil:

Art. 37. A administração pública direta e indireta de qualquer dos Poderes da União, dos Estados, do Distrito Federal e dos Municípios obedecerá aos princípios de legalidade, impessoalidade, moralidade, publicidade e eficiência [...] (BRASIL, Constituição da República Federativa do Brasil)

Dessa forma, sobre os princípios de moralidade e impessoalidade, no sentido de que a ABRACE foi contemplada com a concessão de direito real de uso, a título gratuito, do lote 04-B, no SAIN, onde foi edificado o Hospital da Criança José de Alencar, sem procedimento licitatório, primeiramente, sobre o princípio da moralidade, nas palavras dos doutrinadores, Márcio Fernando e Elias Rosa, no livro Direito Administrativo - Parte 1, 13 ${ }^{a}$ edição, seu conceito é um pouco mais complexo que os demais, pois está ligado à ética, boa-fé e lealdade, indo mais além de uma proibição administrativa de ferir a lei - trata-se da proibição de ferir a honestidade, os bons costumes:

Corresponde à proibição de a atuação administrativa distanciar-se da moral, dos princípios éticos, da boa-fé, da lealdade. Já se disse que o conteúdo do princípio seria "o conjunto de regras tiradas da disciplina interior da Administração" (Maurice Hauriou), contudo, ante o sistema legal pátrio, significa mais: que a atuação administrativa não pode contrariar, além da lei, a moral, os bons costumes, a honestidade, os deveres de boa administração. Se da atuação do agente público resultar a inobservância de um padrão de moral, ainda que comum e não propriamente administrativa, redundará a edição de ato inválido, porque ilegal. A moralidade, como princípio, é de difícil conceituação e sugere sua dependência do princípio da legalidade. Mas ao expressá-lo o constituinte 
Artigo original

Hegemonia - Revista Eletrônica do Programa de Mestrado em Direitos Humanos, Cidadania e Violência/Ciência Política do Centro Universitário Unieuro

ISSN: $1809-1261$

UNIEURO, Brasília, número 26, Janeiro a Junho de 2019, pp. 114-151.

desejou dar-lhe conteúdo próprio e aplicável à Administração Pública. Diz-se, então, que a moral que guia o princípio não é a moral comum, mas a tirada da conduta interna da Administração. Significa dizer, a moral que se relaciona ao princípio é jurídica, e não subjetiva, ligada a outros princípios da Administração e aos princípios gerais de direito. (FERNANDO, Márcio. ROSA, Elias. Direito Administrativo - Parte 1, 2012)

Quanto ao princípio da impessoalidade, o qual também foi violado, seu conceito é abordado da seguinte maneira pelos mesmo doutrinadores:

O segundo princípio expresso no art. 37, caput, da Constituição, agasalha três abordagens distintas. Significa tanto a atuação impessoal, genérica, ligada à finalidade da atuação administrativa que vise à satisfação do interesse coletivo, sem corresponder ao entendimento do interesse exclusivo do administrado, como também significa a imputação da atuação do órgão ou entidade estatal, não o sendo quanto ao agente público, pessoa física, como ainda a isonomia, porque obrigatório o tratamento igualitário de todos os administrados. As três abordagens encontram correspondência com o texto constitucional. (FERNANDO, Márcio. ROSA, Elias. Direito Administrativo - Parte 1, 2012)

Sobre o princípio da isonomia e legalidade, houve a violação dos mesmos, uma vez que o ICIPE teria "se beneficiado pelos atos ímprobos dos corréus, que perpetraram condutas direcionadas a possibilitar que referido instituto se qualificasse como Organização Social, mesmo sem o preenchimento dos requisitos legais, permitindo, com isso, que o ICIPE firmasse o Contrato de Gestão no 001/2011-SES, sem prévia seleção pública, além de ter efetuado contratação de pessoal em desconformidade com o regramento contido no artigo 
Artigo original

Hegemonia - Revista Eletrônica do Programa de Mestrado em Direitos Humanos, Cidadania e Violência/Ciência Política do Centro Universitário Unieuro

ISSN: 1809-1261

UNIEURO, Brasília, número 26, Janeiro a Junho de 2019, pp. 114-151.

$1^{\circ}$ do Decreto n $30.136 / 2009$ ”, como consta na sentença do juiz Paulo Afonso Cavichioli Carmona. Assim, o site "princípios constitucionais", assim define o princípio da isonomia:

Também conhecido como princípio da igualdade, representa o símbolo da democracia, pois indica um tratamento justo para os cidadãos. É essencial dentro dos princípios constitucionais, porém complexo e para sua completa compreensão é necessário entender o contexto cultural e histórico em que foi criado. Desde muito tempo, esse princípio tem feito parte das antigas civilizações. Ao longo da história, foi muitas vezes desrespeitado, assumindo um conceito errado, por entrar em atrito com os interesses das classes dominantes.

De acordo com a Constituição Federal, o Princípio da igualdade está previsto no artigo $5^{\circ}$, que diz que 'Todos são iguais perante a lei, sem distinção de qualquer natureza'. Esta igualdade é chamada de formal. De acordo com ela, é vetado que os legisladores criem ou editem leis que a violem. O princípio da igualdade garante o tratamento igualitário de acordo com a lei para os cidadãos. (CONSTITUCIONAIS, Site Princípios. Princípio da Isonomia Princípios Constitucionais).

Por fim, no que diz respeito ao princípio da legalidade que, na verdade, é o mais importante princípio da Administração, uma vez que dá origem aos demais princípios, expressa Márcio Fernando e Elias Rosa:

Dentre os princípios da Administração, o da legalidade é o mais importante e do qual decorrem os demais, por ser essencial ao Estado de Direito e ao Estado Democrático de Direito. Constitui, assim, vetor basilar do dito regime jurídico-administrativo. Daí ser 
Artigo original

Hegemonia - Revista Eletrônica do Programa de Mestrado em Direitos Humanos, Cidadania e Violência/Ciência Política do Centro Universitário Unieuro

ISSN: $1809-1261$

UNIEURO, Brasília, número 26, Janeiro a Junho de 2019, pp. 114-151.

necessário fixar: permite-se a atuação do agente público, ou da Administração, apenas se permitida, concedida ou deferida por norma legal, não se admitindo qualquer atuação que não contenha prévia e expressa permissão legal. Ao particular é dado fazer tudo quanto não estiver proibido; ao administrador somente o que estiver permitido pela lei (em sentido amplo). Não há liberdade desmedida ou que não esteja expressamente concedida. Toda a atuação administrativa vincula-se a tal princípio, sendo ilegal o ato praticado sem lei anterior que o preveja. Também assim será se a desobediência for em relação a regulamento ou qualquer outro ato normativo. Do princípio da legalidade decorre a proibição de, sem lei ou ato normativo que permita, a Administração vir a, por mera manifestação unilateral, de vontade, declarar, conceder, restringir direitos ou impor obrigações. (FERNANDO, Márcio. ROSA, Elias. Direito Administrativo - Parte 1, 2012)

4 - Punição estabelecida pelo juiz da $7^{a}$ Vara da Fazenda Pública

Dessa forma, no que tange à violação da Lei de Improbidade Administrativa e afronta aos princípios da legalidade, isonomia, impessoalidade e moralidade administrativa, além da violação de outros dispositivos legais, diz a sentença do Juiz Paulo Afonso Cavichioli Carmona, da $7^{\mathrm{a}}$ Vara da Fazenda Pública:

A questão posta em julgamento cinge-se em saber se os réus praticaram ato de improbidade administrativa em decorrência da: I) concessão de direito real de uso de imóvel público outorgado à ABRACE para construção do Hospital da Criança de Brasília; II) qualificação da ICIPE como Organização Social atuante na área da saúde, sem o atendimento dos requisitos legais; III) ausência de 
Artigo original

Hegemonia - Revista Eletrônica do Programa de Mestrado em Direitos Humanos, Cidadania e Violência/Ciência Política do Centro Universitário Unieuro

ISSN: 1809-1261

UNIEURO, Brasília, número 26, Janeiro a Junho de 2019, pp. 114-151.

procedimento licitatório para escolha da entidade gestora do Hospital da Criança de Brasília; IV) ausência de publicidade dos atos que precederam a assinatura do Contrato de Gestão no 001/2011-SES; V) ausência de planilha apta a justificar os preços contratados; VI) contratação de mão-de-obra de forma irregular; VII) violação da Lei de Responsabilidade Fiscal; e, VIII) ocorrência de terceirização ilícita. (Carmona, Paulo Afonso Cavichioli, TJDFT, juiz titular da $7^{\mathrm{a}}$ Vara da Fazenda Pública, Sentença).

Nesse sentido, o mesmo decide proibir o instituto a participar de celebração de contratos com o poder público, por três anos, a contar da prolação da sentença:

Diante do exposto, JULGO PROCEDENTES os pedidos veiculados na petição inicial, para:

a) CONDENAR RAFAEL DE AGUIAR BARBOSA, agente público para os fins da Lei de Improbidade Administrativa, por ter praticado, dolosamente, conduta que ensejou violação aos deveres de legalidade, impessoalidade, imparcialidade, publicidade, isonomia e da lealdade às instituições, ao subscrever o Contrato de Gestão no 001/2011-SES, sem o prévio procedimento administrativo (chamamento público), transferindo a totalidade da administração e execução das atividades do Hospital da Criança de Brasília a uma entidade privada, que sequer possuía experiência técnica para o desempenho das atividades previstas no pacto, além de não ter dado publicidade aos atos anteriores e necessários à celebração do Contrato de Gestão no 001/2011-SES, afrontando as 
Artigo original

Hegemonia - Revista Eletrônica do Programa de Mestrado em Direitos Humanos, Cidadania e Violência/Ciência Política do Centro Universitário Unieuro

ISSN: 1809-1261

UNIEURO, Brasília, número 26, Janeiro a Junho de 2019, pp. 114-151.

disposições contidas no artigo $9^{\circ}$, incisos V e VI, do Decreto ${ }^{\circ}$ 29.870/08, no inciso VIII do artigo 10 da Lei n ${ }^{\circ} 8.429 / 92$, no artigo 199, $\int 1^{\circ}$, da Carta Política de 1988 e nos artigos $4^{\circ}, \S 2^{\circ}$ e 24 , da Lei $n^{\circ} 8.080 / 90$, violando, assim, o disposto no artigo 11, caput e inciso I, da Lei $\mathrm{n}^{\circ}$ 8.429/92, devendo ser apenado na forma do artigo 12, inciso III, do referido Diploma legal. Destarte, determino a perda de função pública, se houver; a suspensão dos direitos políticos pelo prazo de 5 (cinco) anos; proibição de contratar com o Poder Público ou receber benefícios ou incentivos fiscais ou creditícios, direta ou indiretamente, ainda que por intermédio de pessoa jurídica da qual seja sócio majoritário pelo prazo de 3 (três) anos; ao pagamento de multa civil no valor correspondente a dez subsídios de Secretário Saúde do Distrito Federal à época dos fatos, com correção monetária e juros de mora de 1\% a.m. (um por cento ao mês) a contar da prolação desta sentença;

b) CONDENAR ELIAS FERNANDO MIZIARA, agente público para os fins da Lei de Improbidade Administrativa, por ter praticado, dolosamente, conduta que ensejou violação aos deveres de legalidade, impessoalidade, isonomia, imparcialidade e da lealdade às instituições, ao permitir que o Distrito Federal operacionalizasse o Contrato de Gestão no 001/2011-SES com o ICIPE, sem o prévio procedimento administrativo (chamamento público), violando, assim, o disposto no artigo 11, caput e inciso I, da Lei no 8.429/92, devendo ser apenado na forma do artigo 12, inciso III, do referido Diploma legal. Destarte, determino a perda de função pública, se houver; a suspensão dos direitos políticos pelo prazo de 5 (cinco) anos; proibição de contratar com o 
Artigo original

Hegemonia - Revista Eletrônica do Programa de Mestrado em Direitos Humanos, Cidadania e Violência/Ciência Política do Centro Universitário Unieuro

ISSN: 1809-1261

UNIEURO, Brasília, número 26, Janeiro a Junho de 2019, pp. 114-151.

Poder Público ou receber benefícios ou incentivos fiscais ou creditícios, direta ou indiretamente, ainda que por intermédio de pessoa jurídica da qual seja sócio majoritário pelo prazo de 3 (três) anos; ao pagamento de multa civil no valor correspondente a dez subsídios de Secretário Adjunto de Saúde à época dos fatos, com correção monetária e juros de mora de 1\% a.m. (um por cento ao mês) a contar da prolação desta sentença;

c) CONDENAR MARCO AURÉLIO DA COSTA GUEDES, agente público para os fins da Lei de Improbidade Administrativa, por ter praticado, dolosamente, conduta que ensejou violação aos deveres de legalidade, impessoalidade, imparcialidade e da lealdade às instituições, ao lançar voto pela qualificação do ICIPE como Organização Social atuante na área de saúde, ciente de que desatendidos os comandos normativos insculpidos nos artigos $2^{\circ}$, inciso I, letra h, $3^{\circ}$, incisos I, letras a, b, c, da Lei $\mathrm{n}^{\circ} 4.081 / 2008$ e do artigo $9^{\circ}$, incisos V e VI, do Decreto $\mathrm{n}^{\circ} 29.870 / 08$, violando, assim, o disposto no artigo 11, caput e inciso I, da Lei $n^{\circ} 8.429 / 92$, devendo ser apenado na forma do artigo 12, inciso III, do referido Diploma legal. Destarte, determino a perda de função pública, se houver; a suspensão dos direitos políticos pelo prazo de 5 (cinco) anos; proibição de contratar com o Poder Público ou receber benefícios ou incentivos fiscais ou creditícios, direta ou indiretamente, ainda que por intermédio de pessoa jurídica da qual seja sócio majoritário pelo prazo de 3 (três) anos; ao pagamento de multa civil no valor correspondente a dez subsídios de Membro do Conselho de Gestão das Organizações Sociais - CGOS à época dos fatos, com correção monetária e juros de mora 
Artigo original

Hegemonia - Revista Eletrônica do Programa de Mestrado em Direitos Humanos, Cidadania e Violência/Ciência Política do Centro Universitário Unieuro

ISSN: 1809-1261

UNIEURO, Brasília, número 26, Janeiro a Junho de 2019, pp. 114-151.

de $1 \%$ a.m. (um por cento ao mês) a contar da prolação desta sentença;

d) CONDENAR O INSTITUTO DO CÂNCER INFANTIL E PEDIATRIA ESPECIALIZADA - ICIPE, pessoa jurídica de direito privado, por ter se beneficiado pelos atos ímprobos dos corréus, que perpetraram condutas direcionadas a possibilitar que referido instituto se qualificasse como Organização Social, mesmo sem o preenchimento dos requisitos legais, permitindo, com isso, que o ICIPE firmasse o Contrato de Gestão no 001/2011SES, sem prévia seleção pública, além de ter efetuado contratação de pessoal em desconformidade com o regramento contido no artigo $1^{\circ}$ do Decreto $n^{\circ}$ $30.136 / 2009$, afrontando os preceitos da legalidade, isonomia, impessoalidade e moralidade administrativa, violando, assim, o disposto no artigo 11, caput e inciso I, da Lei no 8.429/92, devendo ser apenado na forma do artigo 12, inciso III, do referido Diploma legal. Destarte, determino a proibição de contratar com o Poder Público ou receber benefícios ou incentivos fiscais ou creditícios, direta ou indiretamente, ainda que por intermédio de pessoa jurídica da qual seja sócio majoritário pelo prazo de 3 (três) anos, a contar da prolação desta sentença. (Carmona, Paulo Afonso Cavichioli, TJDFT, juiz titular da $7^{\text {a }}$ Vara da Fazenda Pública, Sentença). 
Artigo original

Hegemonia - Revista Eletrônica do Programa de Mestrado em Direitos Humanos, Cidadania e Violência/Ciência Política do Centro Universitário Unieuro

ISSN: $1809-1261$

UNIEURO, Brasília, número 26, Janeiro a Junho de 2019, pp. 114-151.

5 - Decisão do desembargador relator Alfeu Machado do Tribunal de Justiça do Distrito Federal (TJDFT)

Tendo em vista a sentença do juiz da $7^{a}$ Vara da Fazenda Pública, no Termo de Audiência de Conciliação, o ICIPE, bem como o Distrito Federal, recorreram da decisão, assim reconheceu o desembargador Alfeu Machado, do TJDFT, em um trecho do Termo de Audiência de Conciliação:

Na hipótese em apreço é evidente a presença de risco de dano grave de difícil ou impossivel reparação, já pode ensejar a interrupção da atuação do ICIPE no Hospital da Criança José de Alencar, e é notória a qualidade e eficiência com que presta seus serviços à população do Distrito Federal.

Nesse ponto, reitero que é incontroverso o atendimento de excelência promovido pela instituição e o risco desse atendimento restar prejudicado diante da deficiência também notória da gestão pública da saúde no Distrito Federal, que é diariamente sentido nesse Egrégio Tribunal de Justiça com milhares de ações em curso para garantir atendimento médico básico pela rede pública local. (MACHADO, Alfeu. TJDFT, relator desembargador, Termo de Audiência de Conciliação).

Dessa forma, decide o desembargador relator, condicionando a continuidade do atendimento do Hospital da Criança de Brasília à população, por meio da administração do ICIPE, ao cumprimento de cinco determinações:

Nesse sentido, estabeleço como condições mínimas para, se o caso, concessão de eventual efeito suspensivo, a serem 
Artigo original

Hegemonia - Revista Eletrônica do Programa de Mestrado em Direitos Humanos, Cidadania e Violência/Ciência Política do Centro Universitário Unieuro

ISSN: $1809-1261$

UNIEURO, Brasília, número 26, Janeiro a Junho de 2019, pp. 114-151.

observadas pelo ICIPE e pelo Distrito Federal, as seguintes determinações:

a) - A apresentação de propostas concretas, com prazos factíveis, para submissão do ICIPE a novo procedimento administrativo tendentes a qualifica-lo como Organização Social, observados todos os critérios legais disciplinadores na Lei Distrital $n^{\circ} 4.081 / 08$, notadamente quanto às disposições imprescindíveis do Estatuto Social, formação e atribuições do Conselho de Administração. Prazo: 90 (noventa) dias úteis.

b) - A apresentação de compromissos formal de realizar contratação de pessoal mediante concorrência ampla e com critérios objetivos de seleção, observando, assim, os critérios do artigo $1^{\circ}$ do Decreto Distrital no 30.136/2009, prestando informações ao Juízo e ao Ministério Público sobre esses procedimentos enquanto tramitar o processo, e sem necessidade de dispensa dos profissionais até então contratados. Prazo: 90 (noventa) dias úteis.

c) - Apresentação em Juízo e divulgação no Diário Oficial e nos sítios eletrônicos do Distrito Federal do programa de trabalho desenvolvido e futuro, discriminado os recursos orçamentários empenhados e programados para empenho, observando-se estritamente os requisitos elencados no artigo $9^{\circ}$, do decreto $n^{\circ}$. 29.870/08 e encaminhando essas informações aos órgãos Ministeriais em atuação no feito e ao Tribunal de Contas do Distrito Federal. Prazo: 90 (noventa) dias úteis.

d) O compromisso do Distrito Federal de promover a fiscalização periódica das atividades do ICIPE, com a devida 
Artigo original

Hegemonia - Revista Eletrônica do Programa de Mestrado em Direitos Humanos, Cidadania e Violência/Ciência Política do Centro Universitário Unieuro

ISSN: $1809-1261$

UNIEURO, Brasília, número 26, Janeiro a Junho de 2019, pp. 114-151.

e) O compromisso do Distrito Federal em realizar chamada pública, com ampla divulgação das condições propostas para o contrato de gestão, na hipótese de renovação ou prorrogação do contrato firmado com o ICIPE, viabilizando, assim, a futura concorrência de outras entidades interessadas. Prazo: 90 (noventa) dias úteis.

Delimitados esses parâmetros, fixo o prazo comum de 5 (cinco) dias úteis para que o ICIPE e o DISTRITO FEDERAL se manifestem sobre as condições ora postas, destacando, mais uma vez, que essas medidas não visam o reconhecimento da procedência da ação originária pelos envolvidos, destinando-se, tão somente a possibilitar a continuidade provisória dos serviços do ICIPE no Hospital da Criança, observada as regras legais pertinentes. (MACHADO, Alfeu. TJDFT, relator desembargador, Termo de Audiência de Conciliação).

6 - A judicialização na área da saúde

Levando-se em consideração o caso concreto que está a ser estudado, o mesmo se enquadra no que atualmente se intitula como "judicialização da saúde”. Assim, nas palavras do professor e doutrinador, além de ministro do Supremo Tribunal Federal, Luís Roberto Barroso, "judicialização" ocorre quando assuntos ligados à política ou à sociedade, ao invés de serem decididas pelo poder legislativo e executivo - o que é mais comum, uma vez que são as instâncias naturalmente políticas - são decididas pelo Judiciário, ou seja, há uma transferência de poder destes dois primeiros poderes, quais sejam, executivo e legislativo, para este último, o poder judiciário: 
Artigo original

Hegemonia - Revista Eletrônica do Programa de Mestrado em Direitos Humanos, Cidadania e Violência/Ciência Política do Centro Universitário Unieuro

ISSN: $1809-1261$

UNIEURO, Brasília, número 26, Janeiro a Junho de 2019, pp. 114-151.

Judicialização significa que algumas questões de larga repercussão política ou social estão sendo decididas por órgãos do Poder Judiciário, e não pelas instâncias políticas tradicionais: o Congresso Nacional e o Poder Executivo em cujo âmbito se encontram o presidente da República, seus ministérios e a administração pública em geral. Como intuito, a judicialização envolve uma transferência de poder para juízes e tribunais, com alterações significativas na linguagem, na argumentação e no modo de participação da sociedade. O fenômeno tem causas múltiplas. Algumas delas expressam uma tendência mundial, outras estão diretamente relacionadas ao modelo institucional brasileiro. (BARROSO, Luís Roberto, Ano do STF: judicialização, ativismo e legitimidade democrática, 2008).

Segundo, ainda, Barroso, a judicialização, além de poder ser, um fenômeno mundial, pode ser, também, um fenômeno nacional ligado ao modelo institucional do país, sua primeira causa foi a redemocratização que ocorreu por meio da promulgação da Constituição de 1988, dando origem, assim, à independência do Poder Judiciário, enquanto um dos poderes do Estado, bem como de seus órgãos, além de criar o Ministério Público:

A primeira grande causa da judicialização foi a redemocratização do país, que teve como ponto culminante a promulgação da Constituição de 1988. Nas últimas décadas, com a recuperação das garantias da magistratura, o judiciário deixou de ser um departamento técnico especializado e se transformou em um verdadeiro poder político, capaz de fazer valer a Constituição e as leis, inclusive em confronto com os outros Poderes. No Supremo Tribunal Federal, uma geração de novos ministros já não deve seu título de investidura ao regime 
Artigo original

Hegemonia - Revista Eletrônica do Programa de Mestrado em Direitos Humanos, Cidadania e Violência/Ciência Política do Centro Universitário Unieuro

ISSN: 1809-1261

UNIEURO, Brasília, número 26, Janeiro a Junho de 2019, pp. 114-151.

militar. Por outro lado, o ambiente democrático reavivou a cidadania, dando maior nível de informação e de consciência de direitos a amplos segmentos da população, que passaram a buscar a proteção de seus interesses perante juízes e tribunais. Nesse mesmo contexto, deu-se a expansão institucional do Ministério Público, com aumento da relevância de sua atuação fora da área estritamente penal, bem como a presença crescente da Defensoria Pública em diferentes partes do Brasil. Em suma: a redemocratização fortaleceu e expandiu o Poder Judiciário, bem como aumentou a demanda por justiça na sociedade brasileira. (BARROSO, Luís Roberto, Ano do STF: judicialização, ativismo e legitimidade democrática, 2008).

Por fim, a segunda causa, segundo, ainda, o ministro, foi a larga constitucionalização, ou seja, diversas matérias trazidas para a Constituição, o que, também, seria uma tendência mundial, a exemplo da Constituição Portuguesa e Espanhola - afinal, constitucionalizar, significa, nada mais, nada menos, que transformar política em direito:

A segunda causa foi a constitucionalização abrangente, que trouxe para a Constituição inúmeras matérias que antes eram deixadas para o processo político majoritário e para a legislação ordinária. Essa foi, igualmente, uma tendência mundial, iniciada com as Constituições de Portugal (1976) e Espanha (1978), que foi potencializada entre nós com a Constituição de 1988. A Carta brasileira é analítica, ambiciosa, desconfiada do legislador. Como intuitivo, constitucionalizar uma matéria significa transformar Política em Direito. Na medida em que uma questão - seja um Direito individual, uma prestação estatal ou um fim público - é disciplinada em uma norma constitucional, ela 
Artigo original

Hegemonia - Revista Eletrônica do Programa de Mestrado em Direitos Humanos, Cidadania e Violência/Ciência Política do Centro Universitário Unieuro

ISSN: 1809-1261

UNIEURO, Brasília, número 26, Janeiro a Junho de 2019, pp. 114-151.

se transforma, potencialmente, em uma pretensão jurídica, que pode ser formulada sob a forma de ação judicial. Por exemplo: se a Constituição assegura o direito de acesso ao ensino fundamental ou ao meio-ambiente equilibrado, é possível judicializar a exigência desses dois direitos, levando ao judiciário o debate sobre ações concretas ou políticas públicas praticadas nessas duas áreas. (BARROSO, Luís Roberto, Ano do STF: judicialização, ativismo e legitimidade democrática, 2008).

Nesse sentido, trazendo a ideia de judicialização para o setor da saúde que, está ligado, intrinsicamente, ao direito à saúde e, também, à vida, prevê a constituição que, o Estado, bem como os seus administradores, ficam obrigados a garanti-lo, uma vez que trata-se de um direito social que abrange toda a sociedade, como está previsto no art. $6 .^{\circ}$ da Constituição Federal de 1988:

Art. 6. São direitos sociais a educação, a saúde, a alimentação, o trabalho, a moradia, o transporte, o lazer, a segurança, a previdência social, a proteção à maternidade e à infância, a assistência aos desamparados, na forma desta Constituição. (BRASIL, Constituição da República Federativa do).

Por sua vez, mais especificamente, sobre o direito à saúde, pode-se destacar o que está expresso no art. 196 da Carta Magna:

Art. 196. A saúde é direito de todos e dever do Estado, garantido mediante políticas sociais e econômicas que visem à redução do risco de doença e de outros agravos e ao acesso universal igualitário 
Artigo original

Hegemonia - Revista Eletrônica do Programa de Mestrado em Direitos Humanos, Cidadania e Violência/Ciência Política do Centro Universitário Unieuro

ISSN: 1809-1261

UNIEURO, Brasília, número 26, Janeiro a Junho de 2019, pp. 114-151.

às ações e serviços para sua promoção, proteção e recuperação.

(BRASIL, Constituição da República Federativa do).

Aliás, segundo o dicionário jurídico, Vocabulário Jurídico, a palavra saúde, significa:

SAÚDE. Originando-se do latim salus (conservação da vida, salvação), designa o vocábulo estado de saúde, ou o estado de sanidade dos seres viventes.

Estar com saúde, ou ter saúde, pois, é exercer normalmente todas as funções dos órgãos.

Correntiamente, porém, exprimindo saúde ou estado de sanidade, é suscetível de qualificação, dizendo-se, assim, boa saúde, saúde regular, ou má saúde, para que se determinem a sanidade perfeita, a sanidade não muito respeitada e a má sanidade.

Constitui um dos direitos sociais, previstos constitucionalmente. É da competência comum da União, dos Estados e do Distrito Federal e dos Municípios cuidar da saúde. (SILVA, De Plácido e, Vocabulário Jurídico, 2004)

Tendo em vista o rol de direitos constitucionais, por ora, apresentados, a conduta de não garantir o direito à saúde e, portanto, o direito à vida, vai na linha contrária ao pensamento constitucional dos direitos fundamentais que estão previstos no caput do art. $5^{\circ}$, da Constituição:

Art. 5. Todos são iguais perante a lei, sem distinção de qualquer natureza, garantindo-se aos brasileiros e aos estrangeiros residentes no País a inviolabilidade do direito à vida [...] (BRASIL, Constituição da República Federativa do). 
Artigo original

Hegemonia - Revista Eletrônica do Programa de Mestrado em Direitos Humanos, Cidadania e Violência/Ciência Política do Centro Universitário Unieuro

ISSN: 1809-1261

UNIEURO, Brasília, número 26, Janeiro a Junho de 2019, pp. 114-151.

Tendo esse pensamento como base, portanto, a judicialização da saúde ocorre quando os pacientes não têm acesso, por meio do SUS (Sistema Único de Saúde) ou mesmo planos privados, a medicamentos, exames, cirurgias e até tratamentos e, assim, recorrem ao judiciário, como forma de garantir seus direitos, nesse caso, o direito fundamental a ter saúde.

Aliás, segundo uma matéria da Folha de São Paulo, do ano de 2016, tem crescido nos últimos anos, o número de processos e de gastos do governo federal e governos estaduais, com ações judiciais tendo como matéria, o direito à saúde. Segundo ainda o jornal, no que diz respeito ao Estado de São Paulo, nos últimos cinco anos, o total de condenações quase dobrou. Ou seja, de 9.385 em 2010, foi para 18.045 em 2016.

7 - Considerações finais

Tendo em vista o caso concreto exposto, bem como a reflexão sobre o tema da judicialização, mais especificamente, a judicialização da saúde, seu conceito e causas de surgimento, é possível perceber que a condenação do ICIPE por improbidade administrativa, a decisão do juiz titular da $7^{\text {a }}$ Vara da Fazenda Pública, Paulo Afonso Cavichioli Carmona, sobretudo, a decisão do desembargador relator, Alfeu Machado, são exemplos atuais da judicialização da saúde no Brasil, principalmente, no Distrito Federal.

A primeira sentença reflete a preocupação com a norma, mas não com o ser humano, uma vez que poderia causar uma brusca mudança de gestão sem levar em consideração o aspecto humanista, indo na linha contrária ao ordenamento jurídico moderno que propõe a dignidade humana, o ser humano como ser sagrado, no centro e a frente de todas as ações do Estado. Que a norma deve ser cumprida, isso parece lógico. O que já é discrepante, é abandonar o aspecto humano sob o argumento da legalidade e moralidade. Mais imoral e ilegal seria pegar crianças inocentes e jogá-las em valas comuns da gestão inoperante do Estado: se há conflito, então a dignidade humana deve prevalecer em toda e qualquer situação. O sagrado, que é o ser humano, deve ser respeitado. E em havendo divergência, 
Artigo original

Hegemonia - Revista Eletrônica do Programa de Mestrado em Direitos Humanos, Cidadania e Violência/Ciência Política do Centro Universitário Unieuro

ISSN: 1809-1261

UNIEURO, Brasília, número 26, Janeiro a Junho de 2019, pp. 114-151.

deve-se atualizar normas de modo a tornar o sistema de saúde pública melhor, e não rebaixar a qualidade de atendimento por razões que podem ser ajustadas em um processo formal.

Assim, percebe-se haver neste caso, um paradigma, um confronto entre princípios, qual seja, o de seguir a ordem legal - uma vez que a OS que administra o hospital, foi condenada por improbidade administrativa, além de ter violado, também, alguns dos princípios do Direito Administrativo, como moralidade, impessoalidade, legalidade e isonomia - ou o de se garantir o direito à saúde e à vida e, nesse caso, apesar da legalidade ocorrer como uma condição para que o acesso ao direito à saúde e à vida possam existir, o direito à saúde é o que vence tal confronto, como está reflexo na decisão presente no Termo de Audiência de Conciliação. Ou seja, o impacto de uma decisão na perspectiva do bem social é sempre tão grande que, nesse caso, colocaria em risco a vida de inúmeras crianças, embora, também, não se deva menosprezar, mas reconhecer, o quão necessário para a sociedade, é o papel exercido pelo juiz da $7^{\text {a }}$ Vara da Fazenda Pública, bem como pelo Ministério Público e desembargador do Tribunal de Justiça do Distrito Federal.

Aliás, pode-se perceber isso, quando a segunda instância resolve deixar o ICIPE a continuar administrando o Hospital da Criança de Brasília José Alencar (HCB), desde que, também, o mesmo passe a observar as determinações legais, afinal, como já disse o ministro Luís Roberto Barroso no que diz respeito à importância da judicialização, “com a recuperação das garantias da magistratura, o judiciário deixou de ser um departamento técnico especializado e se transformou em um verdadeiro poder político, capaz de fazer valer a Constituição e as leis, inclusive em confronto com os outros Poderes [...] Em suma: a redemocratização fortaleceu e expandiu o Poder Judiciário, bem como aumentou a demanda por justiça na sociedade brasileira".

\section{BIBLIOGRAFIA}

AGÊNCIA BRASÍLIA DF. Gestão do Hospital da Criança de Brasília permanece com o Icipe.

Fonte: https://agenciabrasilia.df.gov.br > Acesso em: 03 de julho. 2018. Fonte: 
Artigo original

Hegemonia - Revista Eletrônica do Programa de Mestrado em Direitos Humanos, Cidadania e Violência/Ciência Política do Centro Universitário Unieuro

ISSN: 1809-1261

UNIEURO, Brasília, número 26, Janeiro a Junho de 2019, pp. 114-151.

BARROSO, Luís Roberto. Ano do STF: judicialização, ativismo e legitimidade democrática. Fonte: https://www. Conjur.com.br > 2008-dez-22. Acesso em: 30 de junho. 2018.

BIANCARELLI, Aureliano. Capozoli, Emiliano. Criança e vida. Fundação Banco do Brasil. Editora Publisher Brasil LTDA. São Paulo, setembro de 2006.

BRASIL, Constituição da República Federativa. Fonte: www.planalto.gov.br > constituição > co... Acesso em: 03 de julho 2018.

BRASÍLIA, Hospital da Criança de. Hospital da Criança de Brasilia José Alencar - 5 anos.

BRASÍLIA, Hospital da Criança de. Entrevista esclarece funcionamento do HCB. Fonte: www.hcb.org.br > noticias > geral > entre... Acesso em: 30 de junho. 2018.

BRASILIENSE, Correio. Instituto entrega gestão do Hospital da Criança de Brasília ao GDF. Fonte: Acesso: https://www.correiobraziliense.com.br>... Acesso em: 25 de junho. 2018.

CONSTITUCIONAIS, Princípios. Princípio da Isonomia - Princípios Constitucionais. Fonte: princípios-constitucionais.info>principi... Acesso: 01 de julho. 2018.

FERREIRA, Aurélio Buarque de Holanda. Mini Aurélio Século XXI - O minidicionário da língua portuguesa. Editora Nova Fronteira. $4^{a}$ edição revista e ampliada do minidicionário Aurélio $9^{\mathrm{a}}$ impressão - Rio de Janeiro, 2002.

FERREIRA, Roberto Nogueira. Hospital da Criança de Brasilia, ABRACE/ICIPE - HCB (A Brasília que deu certo).

FERNANDO, Márcio. ROSA, Elias. Sinopses jurídicas: Direito Administrativo - Parte I. Editora Saraiva. $13^{a}$ edição, 2012. $4^{a}$ tiragem, 2015. São Paulo.

PAULO, FOLHA DE SÃO. Entenda a judicialização da saúde e debate do STF obre acesso a remédios. Fonte: www1.folha.uol.com.br > 2016/09. Acesso em: 30 de junho. 2018.

SALERNO, Felipe. Ação de improbidade administrativa. Fonte: andegivagos.blogspot.com > 2014/11 > a... Acesso em: 03 de julho. 2018.

SILVA, Plácido e. Vocabulário jurídico. 24ª edição. Editora Forense, Rio de Janeiro, 2004. Páginas 707, 714, 715, 930 e 1257. 
Artigo original

Hegemonia - Revista Eletrônica do Programa de Mestrado em Direitos Humanos, Cidadania e Violência/Ciência Política do Centro Universitário Unieuro

ISSN: 1809-1261

UNIEURO, Brasília, número 26, Janeiro a Junho de 2019, pp. 114-151.

TERRITÓRIOS (TJDFT), Tribunal de Justiça do Distrito Federal e dos Territórios. Consulta processual. Fonte: http://cache-internet.tjdft.jus.br. Acesso em: 01 de julho. 2018. TERRITÓTIOS (TDDFT), Tribunal de Justiça do Distrito Federal e dos Territórios. Consulta processual. Termo de audiência de conciliação. Fonte: https://pje2i.tjdft.jus.br/pje/ConsultaPublica/DetalheProcessoConsultaPublica/listView.s eam?ca $=4 a 96 d 2 b 0 a 58 d 7544 e 350 e c 63 b 21 d 5 e c 89 c c e f 146623 d 632 a$. Acesso em: 02 de julho. 2018. 